\title{
Patient-reported outcome measures for pain in women with pelvic floor disorders: a systematic review
}

\author{
Maisie Ralphsmith ${ }^{1}\left[\right.$ ] Susannah Ahern ${ }^{1} \cdot$ Joanne Dean $^{1} \cdot$ Rasa Ruseckaite $^{1}$
}

Received: 6 September 2021 / Accepted: 7 February 2022 / Published online: 2 March 2022

(c) The Author(s) 2022

\begin{abstract}
Introduction and hypothesis Patient-reported outcome measures (PROMs) are helpful instruments when measuring and reporting changes in patient health status (Al Sayah et al. J Patient Rep Outcomes 5 (Suppl 2):99, 2021) such as the healthrelated quality of life (HrQoL) of women with pelvic organ prolapse (POP) and stress urinary incontinence (SUI). The Australasian Pelvic Floor Procedure Registry (APFPR) aims to increase capacity for women to report surgical outcomes through the collection of HrQoL data (Ruseckaite et al. Qual Life Res. 2021) but currently lacks a pain-specific PROM for women with pelvic floor disorders (PFDs), particularly POP and SUI. This review aims to systematically review the existing literature and identify instruments that measure pain in women with POP and SUI for inclusion within the APFPR, which reports on complications from these conditions.

Methods We conducted a literature search on OVID MEDLINE, Embase, CINAHL, PsycINFO and EMCARE databases in addition to Google Scholar and grey literature to identify studies from inception to April 2021. Full-text studies were included if they used PROMs to measure pain in women with POP and SUI. Two authors independently screened articles, extracted data and assessed methodological quality.

Results From 2001 studies, 23 publications describing 19 different PROMs were included for analysis. Eight of these instruments were specific to the pelvic floor; four were only specific to pain and used across multiple disorders; three were generic quality of life instruments and four were other non-validated instruments such as focus group interviews. These instruments were not specific to pain in women with POP or SUI, as they did not identify all relevant domains such as the sensation, region and duration of pain, or incidents where onset of pain occurs.

Conclusions The findings of this review suggest there are no current PROMs that are suitable pain-specific instruments for women with POP or SUI. This knowledge may inform and assist in the development of a new PROM to be implemented into the APFPR.
\end{abstract}

Keywords Pain $\cdot$ Patient-reported outcome measures $\cdot$ Pelvic floor disorder $\cdot$ Public health $\cdot$ Registry

\section{Introduction}

Pelvic floor disorders (PFDs) involve dysfunction of the muscles within the pelvic floor, where the pelvic muscles weaken or tighten leading to complications [1]. These complications can include stress urinary incontinence (SUI) and pelvic organ prolapse (POP). The International Urogynecological Association (IUGA) and International Continence Society (ICS) defines POP as the descent of one or more of

Rasa Ruseckaite

rasa.ruseckaite@monash.edu

1 Department of Epidemiology and Preventive Medicine, Monash University, Melbourne, Victoria 3004, Australia the anterior vaginal wall, posterior vaginal wall, uterus or apex of the vagina [2]. In addition, SUI refers to the involuntary loss of urine on effort or physical exertion [2]. In Australia, up to $50 \%$ of women are affected by SUI and $9 \%$ are symptomatic for POP [3], with a 19\% lifetime risk of requiring a pelvic floor reconstructive procedure [4]. Until recently, of the surgical interventions for SUI and POP, it was estimated that approximately $25 \%$ involve the use of a mesh product with an estimated 150,000 mesh devices being implanted in Australia since 1998 [5].

A number of women have reported adverse events such as chronic pain and erosion of mesh into the vagina [6] in response to undergoing pelvic floor surgical procedures involving transvaginal mesh implants. Women with 
SUI, and those that have complications following surgery for this disorder, have significantly poorer healthrelated quality of life (HrQoL) than their counterparts without SUI and pain due to surgery. As HrQoL is subject to the patients' experience and personal beliefs, it is best described by patients themselves through patientreported outcome measures (PROMs) [7].

A PROM is defined by the US Federal Drug Administration (FDA) as a "measurement of patient health status elicited directly from the patient" [7]. Many PROMs have been developed to measure HrQoL and can be either generic or specific to a condition, covering several specific domains such as fatigue, depression and pain $[8,9]$. Registries are a proficient means of collecting diseaserelated PROMs as they routinely accumulate data from a large group of patients and thus can evaluate specified outcomes for a population [10]. The Australasian Pelvic Floor Procedure Registry (APFPR) was established in 2019 following a Senate inquiry into complications surrounding pelvic floor procedures that included pain and erosion of mesh into the vagina [11]. Due to the sometimes distressing and complex experience of pain from PFDs or complications associated with POP and SUI surgery, PROMs that measure an array of pain domains by capturing the type and range experienced in these circumstances can support early identification of relevant pain and the clinical management of patients undergoing these procedures [12]. The registry, which aims to provide support to women to report health outcomes regarding POP and SUI, would therefore benefit immensely from the inclusion of a pain-specific PROM.

Following an acceptability study conducted by the APFPR of PROMs in women following procedures for POP and SUI, it was found that women did not believe that current pain instruments were suitable for the registry [13]. Current PROMs from this study failed to recognize the sensation, region or duration of pain, or incidents where onset of pain occurs in women treated surgically for POP or SUI. While existing PROMs may have aspects that are relevant, there is not yet an instrument that covers all of these domains or where all questions are relevant for these groups of patients. Pain following surgery for POP or SUI is complex as it can exist for a variety of reasons including patientrelated factors, the underlying conditions of the disorders, post-operative healing or a range of post-surgical complications including mesh exposure, infection, urinary retention and nerve injury [14]. A greater understanding and analysis of the pain may point to the underlying pathophysiology of this symptom, leading to further clinical investigation and appropriate health service management of the underlying cause [15].
The aim of this study was to review the existing literature and to identify whether there is a current PROM that measures pain in adult women suffering from POP or SUI for inclusion in the APFPR, which specifically reports complications from these two conditions.

\section{Materials and methods}

This systematic review was performed following the Preferred Reporting Items for Systematic review and MetaAnalysis (PRISMA) guidelines [16]. The databases searched include OVID MEDLINE, Embase, CINAHL, PsycINFO and EMCARE from inception to April 2021. Google Scholar was also searched as grey literature, but no additional papers were found. This review was registered on PROSPERO (ID: CRD42021250117). The initial MEDLINE search strategy included search terms "patient reported outcome measures" OR "patient health questionnaire" OR "self-report" OR "surveys" OR "questionnaires" OR "quality of life" OR "health related quality of life" OR "perception" AND "pelvic floor disorders" OR "pelvic floor dysfunction". After the search strategy was finalized in MEDLINE, it was carried out in other databases and adapted as required using $\mathrm{MeSH}$ trees. The detailed search strategy is available as Supplementary material. The search was limited to the English language and human participants only (see Fig. 1).

\section{Eligibility criteria}

We included quantitative and qualitative studies focusing on pain and PFDs involving POP and SUI. No restriction on year of publication was applied. Subjects were women, both inpatients and outpatients. Articles involving only male participants were excluded. Studies without a comparator were considered for inclusion. The main outcome of our analysis was to identify and evaluate all existing instruments used to measure pain in women with POP and SUI.

\section{Screening and selection}

The first stage of screening involved two reviewers (MR, $\mathrm{RR}$ ) reading titles and abstracts of all articles identified by the search. Any articles that clearly did not meet the inclusion criteria were removed. Exclusion criteria were studies where the article was not available in the English language as well as conference abstracts and editorials. Full texts of remaining articles were then read by two reviewers (MR, RR). The numbers of studies at each stage of the search were recorded using the PRISMA flow diagram. 
Fig. 1 Preferred Reporting Items for Systematic review and Meta-Analysis (PRISMA) flowchart showing selection of articles for review

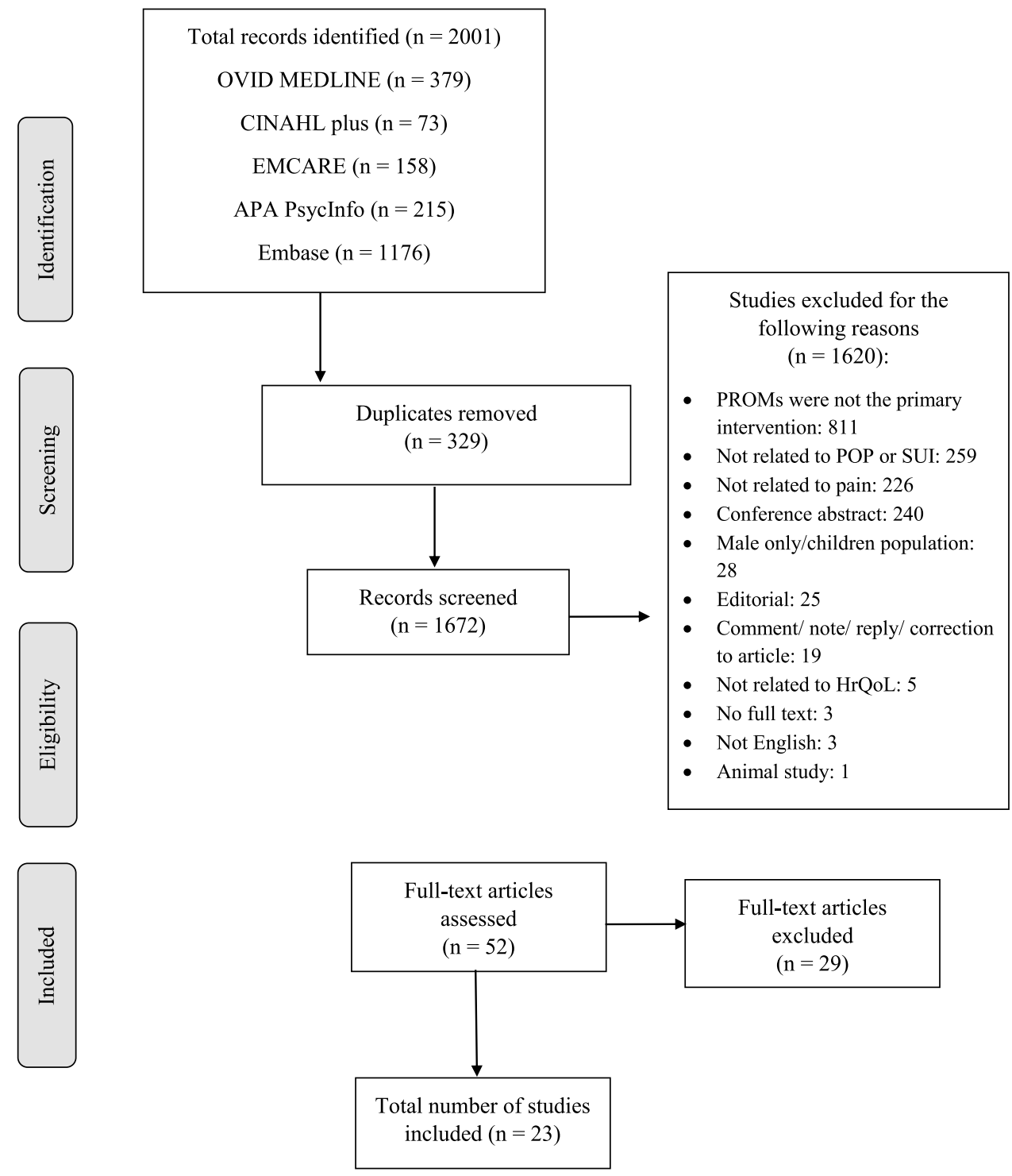

\section{Data extraction}

A data extraction form was constructed to summarize selected studies in line with the outcomes of the systematic review. The form was tested on a small number of articles and revised as necessary.

The following information was extracted:

- Type of study (cross-sectional, longitudinal, validation, development, review);

- Study population (number of participants, adults);

- Mean age of participants where provided;

- Setting in which PROM(s) administered (inpatient, outpatient, clinical trial);

- PROM(s) used;

- Type of PROM(s) (generic, specific);
- Time points PROM(s) administered (pre- or post-diagnosis, stage of study);

- Method of administration (interview, paper, online);

- Key findings of study.

A descriptive synthesis of results was undertaken, organized thematically by type, context, frequency, modes and methods of administration each measure.

The quality of the studies was assessed using the COnsensus-based Standards for the selection of health Measurement INstruments (COSMIN) risk of bias checklist [17]. The COSMIN tool was chosen as it is specifically designed for studies using PROMs. This tool includes assessment of ten domains, and each category was classified as very good, adequate, doubtful or inadequate, if applicable. Results are summarized into a table presenting the lowest score for each property [17]. 


\section{Results}

\section{Search results}

The search yielded 2001 results. After duplicates were deleted, 1672 articles remained. Studies were screened in two phases. An initial screen of titles and abstracts was conducted by two reviewers (MR, RR), which identified 52 articles that fit the inclusion criteria. A further screen of full texts eliminated 29 articles that met the exclusion criteria.

The final number of studies included in the review was 23 articles. The numbers at each stage are outlined in Fig. 1.

\section{Risk of Bias}

Two authors (MR, RR) independently assessed the risk of bias of each of the studies following the COSMIN checklist. Several papers in this review did not validate the instruments used in their studies and thus were not critically appraised. The quality of the results was assessed after data extraction and a full risk of bias table can be found in the Supplementary material.

The COSMIN criteria are used to discern whether the psychometric properties of PROMs have been evaluated using rigorous measures so that reviewers can evaluate the quality of the instrument. For example, the most evaluated property was reliability, where a majority (59\%) of instruments scored as 'adequate', followed by $25 \%$ as 'very good'. This suggests that most instruments that could be tested for reliability were consistent in their measurements of pain. The second most common property was hypothesis testing for construct validity, where $90 \%$ of the eligible instruments scored as 'adequate'. This suggests that most PROMs assessed were adequately consistent with hypotheses based on the assumption that the PROM validly measures the construct to be measured.

\section{General findings}

Twenty-three full texts were included in analysis. Studies were undertaken from 1998 to 2020, with the majority $(n=18,78 \%)$ published between 2011 and 2020 and 22\% $(n=5)$ published between 1998 and 2010. All studies analysed PFDs, with 43\% ( $n=10)$ specifically reporting on SUI [18-27] and $13 \%(n=3)$ focusing solely on POP [28-30]. Three studies included patient groups of women post-birth [26, 29, 31], and four studies recruited women who would have or had surgery for a POP or SUI [30, 32-34]. Most $(n=7,30 \%)$ studies were conducted in the USA [21, 30, $32,35-38]$. There were three (13\%) full texts published in Europe $[22,31,39]$, three $(13 \%)$ in the UK $[20,29,40]$ and three (13\%) in South America [23, 24, 26]. Other studies $(n=3,13 \%)$ were conducted across multiple nations [18, $19,34]$ or in Asia $(n=3,13 \%)[27,41]$ and one $(4 \%)$ in Canada [33].

\section{PROMs identified}

We identified 19 different PROMs that focussed on pain across 23 full-text articles included in this review (see Table 1).

Most $(n=12,52 \%)$ of the studies reported both generic and specific instruments. The next most frequent were articles that contained only condition-specific PROMs $(n=8$, $35 \%$ ), followed by publications reporting generic instruments $(n=3,13 \%)$. There was one study reporting a telephone survey [37], one semi-structured interview [42] and one study involving focus groups [32].

\section{Pain-specific instruments}

There were four pain-specific instruments; however, none were targeted to the pelvic floor or related/referred pain. Pain-specific instruments were reported in four (17\%) articles $[22,27,33,43]$. The Brief Pain Inventory (BPI) was used once by Tincello et al. [43] to measure 'post-operative pain' on a scale of 0 (no) to 10 (severe). The Pain Catastrophizing Scale (PCS) was used once by Larouche et al. [33] to measure 'pre-operative pain' with a score of 0 to 52. The McGill Pain questionnaire measured 'post-operative pain' in the same article, ranging from 0 to 10 [33]. The visual analogue scale (VAS) was utilized in three (13\%) studies $[22,27,43]$ and thus was the most used pain-specific instrument in this systematic review. The VAS measured 'pain' on a scale of 0 (no pain) to 10 (pain as bad as it could be) [44] pre- [43], peri- and post-operatively [22] in women who underwent surgery for a PFD as well as in women who attended a urology or gynaeco-urology clinic for a PFD [27].

\section{PFD-specific instruments}

Nearly half $(42 \%)$ of the instruments identified in this review were condition-specific relating to POP or SUI. Most instruments covered just one area of pain, whether that was described as just 'pain' or 'bodily pain', for example; yet two, the electronic Personal Assessment Questionnaire-Pelvic Floor (ePAQ-PF) and the Genitourinary Pain Index (GUPI), covered an array of pain-related domains [45, 46]. Dua et al. [40] and Elenskaia et al. [29] utilized ePAQ-PF to measure vaginal pain, bladder pain, pain relieved by micturition, dragging pain and pain during or after sex. Cella et al. [21] validated the Lower Urinary Tract Dysfunction Research Network Symptom Index-29 (LURN SI-29) against GUPI, which measured pain at entrance to the vagina, pain in the 
Table 1 Identified instruments and how they measured pain

\begin{tabular}{|c|c|}
\hline Instrument & How pain was measured \\
\hline \multicolumn{2}{|l|}{ Pain specific } \\
\hline BPI & Pain (not specific to PFDs) \\
\hline Pain Catastrophizing Scale (PCS) & Pain (not specific to PFDs) \\
\hline $\begin{array}{l}\text { Short Form McGill Pain Question- } \\
\text { naire (SFMPQ) }\end{array}$ & Post-operative pain (not specific to PFDs) \\
\hline VAS & Residual pain, mean pain intensity, perceived suffering (not specific to PFDs) \\
\hline \multicolumn{2}{|l|}{ Condition specific } \\
\hline ePAQ-PF & Vaginal pain, bladder pain, pain relieved by micturition, dragging pain, pain and sex \\
\hline FSFI & Pain during sexual intercourse, rating of pain \\
\hline GUPI & Pain at entrance to vagina, pain in the vagina, pain in the urethra, pain during or after sexual intercourse \\
\hline ICIQ (ICIQ-VS, ICIQ-UI-SF) & ICIQ-VS: awareness of dragging pain in lower abdomen \\
\hline LURN SI-29 & Bladder pain \\
\hline PFDI (PFDI-20, PFDIQ-SF20) & Pain/discomfort in the lower abdomen or genital region \\
\hline PISQ (PISQ 12, PISQ-IR) & Pain during sexual intercourse, pain stopping one from being sexually active \\
\hline UDI-6 & Pain, pain in lower abdominal/genital area \\
\hline \multicolumn{2}{|l|}{ Generic } \\
\hline EQ-5D-5L & Pain, pain/discomfort (not specific to PFDs) \\
\hline KHQ & Sensation of pain, pain in body part (not specific to PFDs) \\
\hline SF-36 & Bodily pain (not specific to PFDs) \\
\hline \multicolumn{2}{|l|}{ Other } \\
\hline Focus groups & Ranking of pain as an adverse effects post-surgery \\
\hline Other non-validated questions & $\begin{array}{l}\text { Expectation of post-operative pain, self-reported pain tolerance before and after surgery in both POP } \\
\text { and SUI groups }\end{array}$ \\
\hline Pain question & Pain as a patient symptom after surgery for POP \\
\hline Semi structured interview & Pain reported as 'pelvic floor problems' post-partum \\
\hline
\end{tabular}

BPI: Brief Pain Inventory

ED-5D-5L: 5 level EuroQol 5

ePAQ-PF: the electronic Personal Assessment Questionnaire-Pelvic Floor

FSFI: Female Sexual Function Index

GUPI: Genitourinary Pain Index

ICIQ (-VS, -UI-SF): International Consultation on Incontinence Questionnaire (-Vaginal Symptoms, -Urinary Incontinence-Short Form)

KHQ: King's Health Questionnaire

LURN SI-29: Lower Urinary Tract Dysfunction Research Network Symptom Index-29

PFDI (-20): Pelvic Floor Disability Index (20)

PFDIQ-SF20: Pelvic Floor Distress Inventory Questionnaire-Short Form 20

PISQ (-12, -IR): Pelvic Organ Prolapse Incontinence Sexual Questionnaire (12, IUGA-Revised)

SF-36: 36-Item Short Form Survey

UDI-6: Urinary Distress Inventory-6

VAS: visual analogue scale

vagina, pain in the urethra as well as pain during or after sexual intercourse. Different versions of the Pelvic Floor Distress Inventory (PFDI), including the Pelvic Floor Distress Inventory Questionnaire-Short Form 20 (PFDIQ-SF20) and the Pelvic Floor Disability Index-20 (PFDI-20), were analysed in five different articles for "pain or discomfort in the lower abdomen or genital region" [21, 30, 32, 33, 41]. In fact, five instruments across ten studies measured some sort of pain in the abdominal, vaginal or genital region
[21, 28-30, 32, 33, 37, 40, 41, 47]. Four PROMs [ePAQ-PF, GUPI, the Pelvic Organ Prolapse/Urinary Incontinence Sexual Questionnaire (PISQ) and the Female Sexual Function Index (FSFI)] were used to assess pain during intercourse across multiple articles $[21,24,29,30,35,40,48]$ and two instruments (ePAQ-PF, LURN SI-29) measured bladder pain specifically [21, 29, 40]. URIS-24 [36] did not actually measure pain itself but was validated against the pain domain of the SF-36. Furthermore, ICIQ-UI-SF version of 
the ICIQ tool did not measure pelvic floor pain; however, the ICIQ-VS did, measuring "awareness of dragging pain in lower abdomen" [28].

\section{Generic instruments}

Three different generic HrQoL instruments were identified across multiple articles. The five-level EuroQol 5 (EQ5D-5 L) was used by Tincello et al. [43] and Cashman et al. [49], utilizing one of the five domains in the instrument to measure pain in a "non-specific manner" prior to surgery and 3 months post-surgery. 'Pain/discomfort' associated with urinary incontinence in women was also measured by Dayana et al. [24] using the EQ-5D-5L. Both Dayana et al. [24] and Leroy et al. [26] included the King's Health Questionnaire (KHQ) in their studies, with no mention of a pain domain, but compared this instrument to another HrQoL instrument, the Medical Outcomes Study 36-Item Short Form Health Survey (SF-36), which does have a pain domain. SF36 was utilized in $26 \%(n=6)$ of studies to measure bodily pain $[19,24,26,27,30,41]$ with the questions: "how much bodily pain have you had during the past 4 weeks?" and "how much did pain interfere with your normal work?" [50].

\section{Other non-validated questions to measure pain}

Four papers described other instruments and means to assess pain in women with PFDs, including semi-structured interviews and focus groups. Buurman et al. [42] utilized a semistructured interview in women 1 month and 1 year post-birth to discuss perception of PFDs, where all women $(n=26)$ reported pain, including pain that they were not anticipating. Dunivan et al. [32] utilized focus groups to rank adverse effects, one of which included pain that was 'very severe', 'moderately to somewhat severe' or 'not severe'. Furthermore, Larouche et al. [33] used non-validated questions that addressed post-operative pain, and LeBrun et al. [30] described the inclusion of 'patient reported symptoms of pain' after surgery for POP in the Pelvic Floor Disorders Registry (PFDR).

\section{Discussion}

\section{General findings}

This was the first systematic review to look at PROMs that measure pain in women with POP or SUI. We found that there were no validated condition-specific instruments that incorporated all of sensation, region and duration of pain, and that could capture all clinical scenarios where onset of pain occurs in women who suffer from PFDs and their related surgical complications. PROMs were solely PFDspecific instruments (but not focused on pain as a symptom) [21, 26, 28, 29, 35-37, 40, 47, 48, 51], purely pain-specific instruments (these were general and not created with this population in mind) [22,33], generic instruments (lacking specificity to both pain and women with PFDs) $[19,23,24$, $27,43,49,51]$ or non-validated questions (which could not be standardized to measure pain in another population group) $[30,32,33,42]$. There are a range of pain types that women with POP or SUI may experience, including preoperative pain due to hypertonic pelvic floor/myalgia related to the underlying disorder, typical post-operative pain, atypical post-operative pain due to a surgical complication such as an infection or injury, and longer term pain due to pelvic mesh extrusion or breakdown [52]. The instruments found in this literature review did not capture all of sensation of pain, the region in the body where the pain culminates, how long it lasts or with what activities the pain onset occurs. These aspects of pain are important as they may suggest specific underlying pathophysiology worthy of further investigation as well as providing a more holistic understanding of the impact of the pain on women's HrQoL.

\section{Pain-specific PROMs}

Pain-specific instruments are not suitable to measure pain in women with PFDs as they are not targeted sufficiently to the unique range of issues and pain due to complications that this population can be affected by. The VAS [22, 27, 43] is a universal pain assessment tool and measured pain from 0 (none) to 10 ('worst pain possible') [53]. In addition, the McGill Pain Questionnaire measured 'post-operative pain' ranging from 0 to 10 [33]. The BPI was another instrument measuring post-operative pain on a scale of 0 (no) to 10 (severe) at discharge home or $24 \mathrm{~h}$ after surgery [43]. Furthermore, the PCS measured 'pre-operative pain' with a score of 0 to 52 [33]. Despite allowing for a quick assessment of both acute and chronic pain, the mono-dimensional aspect of these instruments may not be appropriate in revealing the quality of the painful experience or differentiating the types of pain that come with these conditions, or as a result of mesh procedure complications [54]. This could include painful voiding, mesh-related infection or severe vaginal pain aggravated by movements [14]. Additional qualitative descriptions of pain would increase the utility of these instruments, and furthermore, a better understanding of these pain characteristics may aid improvements in managing underlying causes of pain.

\section{PFD-specific PROMs}

The UDI-6 instrument, which is condition specific and used for both POP and SUI, both pre- and post-surgery 
$[37,47]$, asks the question, "Do you experience pain or discomfort in your lower abdominal, pelvic or genital region?" with a ranking of 0 (not at all) to 3 (greatly). This question is suitable to women with PFDs as it targets a specific region of pain, however, fails to recognize different types of pain, as women with these conditions suffer from pressure or heaviness deep in the pelvic area to severe, sharp pains and cramping [55]. An instrument such as the UDI-6, gathering data that one "has pain", is not descriptive enough to inform a health professional about pain type [56]. Other PFD-specific instruments were also not suitable to measure pain in women with PFDs. The ePAQ-PF, despite measuring pain in pelvic floor disorders, consists of 120 questions $[29,40]$. The length of this instrument may result in patient burden. The LURN SI-29 only explores the frequency and time points of bladder pain, failing to uncover the nature and intensity of such pain [21]. Conversely, the GUPI assesses bladder pain symptoms, yet not the onset of such [21]. In addition, the PFDI, where versions were included in five studies [21, $30,33,38,41]$, includes questions such as "Do you usually experience heaviness or dullness in the pelvic area?" with a scale of 'no' or 'yes' and, if yes, a pain rating of 1 to 4. In addition, the ICIQ-VS [28] asks "Are you aware of dragging pain in your lower abdomen?" with scores of 0 (never) to 4 (all the time). Ultimately, while questions like these are specific and more targeted to the population, they fail to retrieve information such as when the heaviness, dullness or dragging pain is felt, with what activities, whether the pain is constant or intermittent and when it first started. These type of ad hoc questions regarding pain do not truly capture the entirety of the pain.

\section{Generic PROMs}

The generic instruments entailed questions that were rather broad, for example, in the SF-36: "How much bodily pain have you had during the past 4 weeks?" with a rating of 'none' to 'very severe' [50]. In addition, the EQ5D-5L [24, 43, 49] asks patients to tick a box about their pain, where having no pain, slight pain, moderate pain, severe pain or extreme pain or discomfort are options. These pain questions may not be suitable for women with PFDs as 'pain or discomfort' in the 'bodily' region is not specific enough and does not inform us of the true sensations of pain. The quality and degree of pain are imperative as complications from procedures may be identified as a source of the patient's pain [57]. Thus, generic PROMs that have pain domains may not be able to capture the full extent of pain suffered by women living with this condition and complications post-surgery [58].

\section{Other non-validated questions to measure pain}

Moreover, non-validated questions regarding pain may better encapsulate a patient's personal experience with pelvic floorrelated pain. Dunivan et al. [32] incorporated the patients' perspective utilizing focus groups at three separate surgery sites to discuss adverse effects, one including pain. A woman mentioned: "I have pain as well in my rectum. It feels like it gets pinched or something" [32]. The ability to converse with these women, compared to ticking a box in a questionnaire, is a benefit as the health professional can further deduce the true sensation, duration and region of pain, and the incidents where onset of pain occurs in women with PFDs. However, questions within focus groups and other semi-structured interviews are non-validated and therefore may not be reliable or applicable across other groups [59] as they are not standardized. A new validated PROM may be able to flag underlying clinical issues, whereby clinicians can further investigate through patient-specific consultation.

\section{Inclusion of pain instrument in the APFPR}

Following review of the available pain questionnaires by clinicians and consumers, it was considered that given the significance of pain as a potential indicator of pathophysiology, as well as its impact on women's HrQoL, there is a need for a new pain-specific PROM in the APFPR for women with POP or SUI. This review of the literature has confirmed that existing validated tools do not meet this need. The inclusion of a pain-related PROM into the APFPR will allow for further investigation of pain, especially as a complication post-surgery, and thus a more nuanced understanding of the impact of the pain on a woman's HrQoL. Consequently, a new PROM developed for and included in the APFPR focusing on accurately measuring pain for POP and SUI could improve the quality of care and QoL of women living with these disorders. The development of a new PROM could be achieved through focus group questions and semi-structured interviews, providing a more personal insight into the woman's experience and their subsequent HrQoL. A validated instrument created from these more 'conversational' type questions would provide huge benefit to the registry. However, a questionnaire that incorporates all pain types found in our search of the literature may be rather extensive. Therefore, it is very important for well conducted semi-structured interviews with women to highlight the most imperative pain types and time points. To do this, one method may be to conduct such interviews with both patients and pelvic floor clinicians and ask them what they deem to be relevant [60]. Furthermore, through qualitative interviews with women who suffer from PFDs themselves, content validity of the PROM may be deduced [60]. 


\section{Strengths and limitations}

This systematic review synthesized data from five databases and thus produces a rather robust body of evidence. It utilized systematic methods to assess study quality. In addition, this review is the first to critically evaluate the types of pain instruments and their subsequent properties in women with POP or SUI. However, this systematic review has a limitations, that of being restricted to English language publications only, where other languages may have provided different insights into pain measurements using PROMs. A further search of grey literature and exterior databases could have been beneficial to include a wider variety of studies.

\section{Conclusion}

This review aimed to identify whether there is a PROM that measures pain specifically for women with POP and SUI for inclusion in the APFPR, which specifically reports complications from these two conditions. We did not find a suitable pain-specific PROM designed for this population, and thus there remains a serious lack of substantial reporting on the $\mathrm{HrQoL}$ in women who continue to suffer pain following pelvic floor surgery. Based on a systematic review of the current literature, we suggest that the next step entails the development of a new instrument for pain, especially pain related to complications due to pelvic floor surgery, and one that will be suitable for inclusion into the APFPR. This new PROM may be suited for both pre- and post-surgery data collection.

Supplementary Information The online version contains supplementary material available at https://doi.org/10.1007/s00192-022-05126-4.

\footnotetext{
Author contributions - M Ralphsmith: manuscript writing, data collection, protocol, project development, data analysis

- S Ahern: manuscript editing

- J Dean: manuscript editing

- R Ruseckaite: manuscript editing, project development
}

Funding Open Access funding enabled and organized by CAUL and its Member Institutions.

\section{Declarations}

\section{Conflict of interest None.}

Open Access This article is licensed under a Creative Commons Attribution 4.0 International License, which permits use, sharing, adaptation, distribution and reproduction in any medium or format, as long as you give appropriate credit to the original author(s) and the source, provide a link to the Creative Commons licence, and indicate if changes were made. The images or other third party material in this article are included in the article's Creative Commons licence, unless indicated otherwise in a credit line to the material. If material is not included in the article's Creative Commons licence and your intended use is not permitted by statutory regulation or exceeds the permitted use, you will need to obtain permission directly from the copyright holder. To view a copy of this licence, visit http://creativecommons.org/licenses/by/4.0/.

\section{References}

1. Pelvic Floor Dysfunction. 2020. https://my.clevelandclinic.org/ health/diseases/14459-pelvic-floor-dysfunction. Accessed 19 Apr 2021.

2. Haylen BT, de Ridder D, Freeman RM, Swift SE, Berghmans B, Lee J, Monga A, Petri E, Rizk DE, Sand PK, Schaer GN. An international urogynecological association (IUGA)/international continence society (ICS) joint report on the terminology for female pelvic floor dysfunction. Neurourol Urodyn. 2010;29(1):4-20. https://doi.org/10.1002/nau.20798.

3. MacLennan AH, Taylor AW, Wilson DH, Wilson D. The prevalence of pelvic floor disorders and their relationship to gender, age, parity and mode of delivery. Bjog. 2000;107(12):1460-70. https://doi.org/10.1111/j.1471-0528.2000.tb11669.x.

4. Smith FJ, Holman CD, Moorin RE, Tsokos N. Lifetime risk of undergoing surgery for pelvic organ prolapse. Obstet Gynecol. 2010;116(5):1096-100. https://doi.org/10.1097/AOG.0b013e3181 f73729.

5. Daly JO, Ahern S, Herkes R, O'Connell HE. The Australasian pelvic floor procedure registry: not before time. Aust N Z J Obstet Gynaecol. 2019;59(4):473-6. https://doi.org/10.1111/ajo.13030.

6. Abbott S, Unger CA, Evans JM, Jallad K, Mishra K, Karram MM, Iglesia CB, Rardin CR, Barber MD. Evaluation and management of complications from synthetic mesh after pelvic reconstructive surgery: a multicenter study. Am J Obstet Gynecol. 2014;210(2):163.e161-8. https://doi.org/10.1016/j.ajog.2013.10. 012.

7. Blackwell LS, Marciel KK, Quittner AL. Utilization of patientreported outcomes as a step towards collaborative medicine. Paediatr Respir Rev. 2013;14(3):146-51. https://doi.org/10.1016/j. prrv.2013.04.003.

8. McKenna SP. Measuring patient-reported outcomes: moving beyond misplaced common sense to hard science. BMC Med. 2011;9:86. https://doi.org/10.1186/1741-7015-9-86.

9. Kingsley C, Patel S. Patient-reported outcome measures and patient-reported experience measures. BJA Education. 2017;17(4):137-44. https://doi.org/10.1093/bjaed/mkw060.

10. Gliklich RE, Dreyer NA, Leavy MB. AHRQ methods for effective health Care. In: Registries for evaluating patient outcomes: a User's guide. Rockville: Agency for Healthcare Research and Quality (US); 2014.

11. Australasian Pelvic Floor Procedure Registry (APFPR). 2019. https://apfpr.org.au/. Accessed 19 Apr 2021.

12. Adam R, Burton CD, Bond CM, de Bruin M, Murchie P. Can patient-reported measurements of pain be used to improve cancer pain management? A systematic review and meta-analysis. BMJ Support Palliat Care. 2017;7(4):0. https://doi.org/10.1136/bmjsp care-2016-001137.

13. Ruseckaite R, Bavor C, Marsh L, Dean J, Daly OJ, Vasiliadis $\mathrm{D}$, Ahern S. Evaluation of the acceptability of patient-reported outcome measures in women following pelvic floor procedures. Qual Life Res. 2021. https://doi.org/10.21203/rs.3.rs-360617/v1.

14. Shah HN, Badlani GH. Mesh complications in female pelvic floor reconstructive surgery and their management: a systematic review. Indian J Urol. 2012;28(2):129-53. https://doi.org/10.4103/09701591.98453 
15. Williams K, Sansoni J, Morris D, Grootemaat P, Thompson C. Patient-reported outcome measures: literature review. Sydney: ACSQHC. 2016.

16. PRISMA. Transparent reporting of systematic reviews and Metaanalyses. 2015. http://www.prisma-statement.org/PRISMAStat ement/FlowDiagram. Accessed 19 Apr 2021.

17. Mokkink LB, Terwee CB, Patrick DL, Alonso J, Stratford PW, Knol DL, Bouter LM, de Vet HCW. The COSMIN checklist for assessing the methodological quality of studies on measurement properties of health status measurement instruments: an international Delphi study. Qual Life Res. 2010;19(4):539-49. https://doi. org/10.1007/s11136-010-9606-8.

18. Bordeianou LG, Anger JT, Boutros M, Birnbaum E, Carmichael JC, Connell KA, De EJB MA, Staller K, Vogler SA, Weinstein MM, Yafi FA, Hull TL. Measuring pelvic floor disorder symptoms using patient-reported instruments: Proceedings of the consensus meeting of the pelvic floor consortium of the american society of colon and rectal surgeons, the international continence society, the american urogynecologic society, and the society of urodynamics, female pelvic medicine and urogenital reconstruction. Female Pelvic Med Reconstruct Surg. 2020;26(1):1-15. https://doi.org/10. 1097/SPV.0000000000000817.

19. Bushnell DM, Martin ML, Summers KH, Svihra J, Lionis C, Patrick DL. Quality of life of women with urinary incontinence: cross-cultural performance of 15 language versions of the I-QOL. Qual Life Res: Int J Qual Life Aspects Treatment, Care Rehabil. 2005;14(8):1901-13. https://doi.org/10.1007/s11136-005-5266-5.

20. Cashman S, Biers S, Greenwell T, Harding C, Morley R, Cooper D, Fowler S, Thiruchelvam N, ObotBSoF N, Urology U. Results of the British Association of Urological Surgeons female stress urinary incontinence procedures outcomes audit 2014-2017. BJU Int. 2019;123(1):149-59. https://doi.org/10.1111/bju.14541.

21. Cella D, Smith AR, Griffith JW, Flynn KE, Bradley CS, Gillespie BW, Kirkali Z, Talaty P, Jelovsek JE, Helfand BT, Weinfurt KP, Group LS. A new outcome measure for LUTS: symptoms of lower urinary tract Dysfunction research network symptom Index-29 (LURN SI-29) questionnaire. Neurourol Urodyn. 2019;38(6):1751-9. https://doi.org/10.1002/nau.24067.

22. Collinet P, Ciofu C, Costa P, Cosson M, Deval B, Grise P, Jacquetin B, Haab F. The safety of the inside-out transobturator approach for transvaginal tape (TVT-O) treatment in stress urinary incontinence: French registry data on 984 women. Int Urogynecol J Pelvic Floor Dysfunct. 2008;19(5):711-5. https://doi.org/10.1007/ s00192-007-0514-6.

23. Dantas THM, Castaneda L, Magalhaes AG, Dantas DS. Linking of assessment scales for women with urinary incontinence and the international classification of functioning, disability and health. Disabil Rehabil: Int Multidisciplin J. 2019;41(12):1443-9. https:// doi.org/10.1080/09638288.2018.1431695.

24. Dayana Maia S, Mariana Luisa Veras F, Karine de Castro B, José Ananias Vasconcelos N, Mônica Oliveira Batista O, Camila Teixeira Moreira V. Impact of urinary incontinence types on women's quality of life. Revista da Escola de Enfermagem da USP. 2017;51:1-8. https://doi.org/10.1590/S1980-220X20160326032 66.

25. DeBeau CE, Kiely DK, Resnick NM. Quality of life impact of urge incontinence in older persons: a new measure and conceptual structure. J Am Geriatr Soc. 1999;47(8):989-94. https://doi.org/ 10.1111/j.1532-5415.1999.tb01295.x.

26. Leroy LS, Moraes MHBM. Urinary incontinence in the puerperium and its impact on the health-related quality of life. Revista Latino-Americana de Enfermagem. 2012;20(2):346-53. https:// doi.org/10.1590/S0104-11692012000200018.

27. Margalith I, Gillon G, Gordon D. Urinary incontinence in women under 65: quality of life, stress related to incontinence and patterns of seeking health care. Qual Life Res: Int J Qual Life Aspects
Treatment, Care Rehabil. 2004;13(8):1381-90. https://doi.org/10. 1023/B:QURE.0000040794.77438.cf.

28. Ekanayake CD, Pathmeswaran A, Herath RP, Perera HSS, Patabendige M, Wijesinghe PS. Validation of the international consultation on incontinence questionnaire-vaginal symptoms (ICIQ-VS) in two south-Asian languages. Int Urogynecol J Pelvic Floor Dysfunct. 2017;28(12):1849-55. https://doi.org/10.1007/ s00192-017-3294-7.

29. Elenskaia K, Thakar R, Sultan AH, Scheer I, Onwude J. Pelvic organ support, symptoms and quality of life during pregnancy: a prospective study. Int Urogynecol J Pelvic Floor Dysfunct. 2013;24(7):1085-90. https://doi.org/10.1007/s00192-012-1935-4.

30. Le Brun EW, Adam RA, Barber MD, Boyles SH, Iglesia CB, Lukacz ES, Moalli P, Moen MD, Richter HE, Subak LL, Sung VW, Visco AG, Bradley CS. Pelvic floor disorders registry: study design and outcome measures. Female Pelvic Med Reconstruct Surg. 2016;22(2):70-6. https://doi.org/10.1097/SPV.0000000000 000237.

31. Buurman MB, Lagro-Janssen AL. Women's perception of postpartum pelvic floor dysfunction and their help-seeking behaviour: a qualitative interview study. Scand J Caring Sci. 2013;27(2):40613. https://doi.org/10.1111/j.1471-6712.2012.01044.x.

32. Dunivan GC, Sussman AL, Jelovsek JE, Sung VW, Andy UU, Ballard A, Jakus-Waldman S, Amundsen CL, Chermansky C, Bann C, Rogers RG. The patient perspective on pelvic floor disorders surgical adverse events. Female Pelvic Med Reconstruct Surg. 2017;23(5 Supplement 1):S17-8. https://doi.org/10.1097/ SPV.0000000000000477.

33. Larouche M, Brotto LA, Koenig NA, Lee T, Cundiff GW, Geoffrion R. Depression, anxiety, and pelvic floor symptoms before and after surgery for pelvic floor dysfunction. Female Pelvic Med Reconstruct Surg. 2020;26(1):67-72. https://doi.org/10.1097/SPV. 0000000000000582.

34. Tincello D, Sculpher M, Tunn R, Quail D, van der Vaart H, Falconer C, Manning M, Timlin L. Patient characteristics impacting health state index scores, measured by the EQ-5D of females with stress urinary incontinence symptoms. Value Health. 2010;13(1):112-8. https://doi.org/10.1111/j.1524-4733.2009. 00599.x.

35. Constantine ML, Pauls RN, Rogers RG, Rockwood T. The prolapse incontinence sexual questionnaire-iuga revised (PISQ-IR); a new summary score. Female Pelvic Med Reconstruct Surg. 2016;22(5 Supplement 1):S63-4. https://doi.org/10.1097/SPV. 0000000000000330.

36. DuBeau CE, Levy B, Mangione CM, Resnick NM. The impact of urge urinary incontinence of quality of life: importance of patients' perspective and explanatory style. J Am Geriatr Soc. 1998;46(6):683-92. https://doi.org/10.1111/j.1532-5415.1998. tb03801.x.

37. Dugan E, Cohen S, Robinson D, Anderson R, Preisser J, Suggs P, Pearce K, Poehling U, McGann P. The quality of life of older adults with urinary incontinence: determining generic and condition-specific predictors. Qual Life Res: Int J Qual Life Aspects Treatment, Care Rehabil. 1998;7(4):337-44. https://doi.org/10. 1023/A:1008898602951

38. Habashy E, Mahdy AE. Patient-reported outcome measures (PROMs) in pelvic floor disorders. Curr Urol Rep. 2019;20(5):22. https://doi.org/10.1007/s11934-019-0888-2.

39. Grzybowska M, Piaskowska-Cala J, Wydra D. Identification of PISQ-IR cutoff scores for impaired sexual function in women with pelvic floor disorders. Neurourol Urodyn. 2019;38(Supplement 3):S28-9. https://doi.org/10.1002/nau.24118.

40. Dua A, Radley S, Jones G, Farkas A. The personal impact of pelvic floor symptoms and their relationship to age. Int Urogynecol J Pelvic Floor Dysfunct. 2014;25(1):117-21. https://doi.org/10. 1007/s00192-013-2167-y. 
41. Chan SS, Pang SM, Lai BP, Choy KW. Quality of life and symptom measurement in Chinese women with pelvic floor disorders: validation study of pelvic floor distress inventory and pelvic floor impact questionnaire. Hong Kong Med. 2017;23(Suppl 2 (3)):38-41.

42. Buurman MBR, Lagro-Janssen ALM. Women's perception of postpartum pelvic floor dysfunction and their help-seeking behaviour: a qualitative interview study. Scand J Caring Sci. 2013;27(2):406-13. https://doi.org/10.1111/j.1471-6712.2012. 01044.x.

43. Tincello DG, Botha T, Grier D, Jones P, Subramanian D, Urquhart C, Kirkemo A, Khandwala S. The TVT worldwide observational registry for long-term data: safety and efficacy of suburethral sling insertion approaches for stress urinary incontinence in women. $\mathbf{J}$ Urol. 2011;186(6):2310-5. https://doi.org/10.1016/j.juro.2011.07. 078.

44. Haefeli M, Elfering A. Pain assessment. Eur Spine J. 2006;15(Suppl 1):S17-24. https://doi.org/10.1007/ s00586-005-1044-x.

45. Jones G, Radley S, Lumb J, Jha S. Electronic pelvic floor symptoms assessment: tests of data quality of ePAQ-PF. Int Urogynecol J Pelvic Floor Dysfunct. 2008;19:1337-47.

46. Clemens JQ, Calhoun EA, Litwin MS, McNaughton-Collins M, Kusek JW, Crowley EM, Landis JR, Urologic Pelvic Pain Collaborative Research N. Validation of a modified National Institutes of Health chronic prostatitis symptom index to assess genitourinary pain in both men and women. Urology. 2009;74(5):983-7, quiz 987.e981-983. https://doi.org/10.1016/j.urology.2009.06.078.

47. Bordeianou LG, Anger JT, Boutros M, Birnbaum E, Carmichael JC, Connell KA, De EJB, Mellgren A, Staller K, Vogler SA, Weinstein MM, Yafi FA, Hull TL, Members Of The Pelvic Floor Disorders Consortium Working Groups On Patient-Reported O. Measuring pelvic floor disorder symptoms using patient-reported instruments: proceedings of the consensus meeting of the pelvic floor consortium of the American Society of Colon and Rectal Surgeons, the international continence society, the American Urogynecologic Society, and the Society of Urodynamics, female pelvic medicine and urogenital reconstruction. Dis Colon Rectum. 2020;63(1):6-23. https://doi.org/10.1097/DCR.0000000000 001529 .

48. Grzybowska ME, Futyma K, Wydra D. Identification of the pelvic organ prolapse/incontinence sexual questionnaire-IUGA revised (PISQ-IR) cutoff scores for impaired sexual function in women with pelvic floor disorders. J Clin Med. 2020;9(1). https://doi.org/ 10.3390/jcm9010013.

49. Cashman S, Biers S, Greenwell T, Harding C, Morley R, Cooper D, Fowler S, Thiruchelvam N, Neurological BSoF, Urodynamic U. Results of the British Association of Urological Surgeons female stress urinary incontinence procedures outcomes audit 2014-2017. BJU Int. 2019;123(1):149-59. https://doi.org/10.1111/ bju. 14541.

50. Care RH. 36-Item Short Form Survey Instrument (SF-36). https:// www.rand.org/health-care/surveys_tools/mos/36-item-short-form/ survey-instrument.html. Accessed 19 Apr 2021.
51. Chan SS, Pang SM, Lai BP, Choy KW. Quality of life and symptom measurement in Chinese women with pelvic floor disorders: validation study of pelvic floor distress inventory and pelvic floor impact questionnaire. Hong Kong Med J. 2017;23(Suppl 2 (3)):38-41.

52. Shah HN, Badlani GH. Mesh complications in female pelvic floor reconstructive surgery and their management: a systematic review. Indian J Urol. 2012;28(2):129-53. https://doi.org/10.4103/09701591.98453.

53. Hawker GA, Mian S, Kendzerska T, French M. Measures of adult pain: visual analog scale for pain (VAS pain), numeric rating scale for pain (NRS pain), McGill pain questionnaire (MPQ), shortform McGill pain questionnaire (SF-MPQ), chronic pain grade scale (CPGS), short Form-36 bodily pain scale (SF-36 BPS), and measure of intermittent and constant osteoarthritis pain (ICOAP). Arthritis Care Res. 2011;63(S11):S240-52. https://doi.org/10. 1002/acr.20543.

54. Passavanti MB, Pota V, Sansone P, Aurilio C, De Nardis L, Pace MC. Chronic pelvic pain: assessment, evaluation, and Objectivation. Pain Res Treat. 2017;2017:9472925. https://doi.org/10.1155/ 2017/9472925.

55. Staff MC. Chronic pelvic pain in women. 2019. https://www. mayoclinic.org/diseases-conditions/chronic-pelvic-pain/sympt oms-causes/syc-20354368.

56. Fink R. Pain assessment: the cornerstone to optimal pain management. Proc (Bayl Univ Med Cent). 2000;13(3):236-9. https://doi. org/10.1080/08998280.2000.11927681.

57. Dydyk AM, Gupta N. Chronic pelvic pain. Treasure Islad (FL): StatPearls Publishing; 2021.

58. van Munster CEP, Uitdehaag BMJ. Outcome measures in clinical trials for multiple sclerosis. CNS Drugs. 2017;31(3):217-36. https://doi.org/10.1007/s40263-017-0412-5.

59. Pieber K, Herceg M, Paternostro-Sluga T, Pablik E, Quittan M, Nicolakis P, Fialka-Moser V, Crevenna R. Reliability, validity, sensitivity and internal consistency of the ICF based basic mobility scale for measuring the mobility of patients with musculoskeletal problems in the acute hospital setting: a prospective study. BMC Musculoskelet Disord. 2015;16:187. https://doi.org/10. 1186/s12891-015-0638-7.

60. Comins JD, Brodersen J, Siersma V, Jensen J, Hansen CF, Krogsgaard MR. Article three in a series of ten how to develop a condition-specific PROM. Scandinavian J Med Sci Sports n/a (n/a). https://doi.org/10.1111/sms.13868.

61. Al Sayah F, Jin X, Johnson JA. Selection of patient-reported outcome measures (PROMs) for use in health systems. J Patient Rep Outcomes. 2021;5(Suppl 2):99. https://doi.org/10.1186/ s41687-021-00374-2.

Publisher's note Springer Nature remains neutral with regard to jurisdictional claims in published maps and institutional affiliations. 